\title{
RESEARCH PAPER \\ THE DETERMINANTS OF DEMAND FOR PUBLIC TRANSPORT SERVICES IN KUMASI, GHANA
}

\author{
M. Poku-Boansi and K. K. Adarkwa \\ Dept of Planning, KNUST, Kumasi \\ mpoku-boansi.cap@knust.edu.gh \\ kwasiadarkwa@knust.edu.gh
}

\begin{abstract}
The objective of the study was to establish the major factors influencing demand as well as develop a demand model for urban passenger transport services in Kumasi, Ghana. Data for this study were obtained from 400 commuters grouped into strata with definite characteristics such as income levels and trip making characteristics using the framework defined by Department of Urban Roads during two main field surveys using the simple random sampling technique. The analysis of the data showed that key determinants such as employment status of commuters, trip duration, and population influence the demand for public transport services in Kumasi. In addition, it was found that Taxi is the dominant mode used in Kumasi, carrying about $44 \%$ of respondents. This is mainly because it is the fastest mode in the city. The minibus is the next patronised mode carrying $32 \%$ of the respondents while Metro Mass Transit buses were the least patronised, even though they have the capacity to carry more passengers. This is mainly because of the long travel time these buses offer to passengers. The study therefore recommends among others, the use of large occupancy vehicles by providing them with exclusive lanes to help reduce travel time to make them the preferred option of commuters.
\end{abstract}

Keywords: Demand, Passenger Transport Services, Public Transport, Passenger-kilometres

\section{INTRODUCTION}

Cities in developing countries often spend between 15 to $25 \%$ of their annual expenditure on the transport system and it is also common to find that between 5 to $10 \%$ of urban household income in developing countries is spent on urban transportation and in some cases, the figure is estimated to be $15 \%$ or more (World Bank, 2004). Mass transport in developing countries is essential for the urban poor who have to rely on walking, cycling and road based public transport to meet most of their travel needs. Several studies have highlighted this important role of mass transportation in the urban economy of most countries (Kwakye et al, 1994). Traditionally, the focus of urban transportation has been on passengers as cities were viewed as locations of utmost human interactions with 
61

\section{Poku-Boansi and Adarkwa}

intricate traffic patterns linked to commuting, commercial transactions, and leisure activities. Several researchers including Mbara (2006), Okoko (1998) and Lee et al (1974) have underscored the importance of analysing the demand for urban transport services. However, in $\mathrm{Ku}$ masi, very little has been done in undertaking detail analysis of the demand for urban transport services which invariably has led to little intervention in satisfying the travel needs of commuters.

According to the Transport Research Laboratory (TRL) (2004), annual number of passenger trips (APT), annual passenger kilometres (APK), and annual passenger revenue (APR) are the three main indicators for estimating demand for urban public transport services. For the purpose of this study, APK is used due to data availability. The rationale behind the demand analysis used in the paper is generally found in economic theory where passengers choose among alternatives to maximize their utility; that is, to choose the package of goods and services (trips) which they consider best among all the packages available to them, bearing in mind the various constraints, which might be imposed on their choice.

\section{OVERVIEW OF URBAN TRANSPORTA-} TION SERVICES IN KUMASI

Kumasi, which had a population of $1,708,000$ in 2008 and an annual growth rate of 3.69 (UNHABITAT, 2008) is located approximately in the central part of Ghana and all the transportation systems both on and above ground, converge in the city. At the time of the study, $\mathrm{Ku}-$ masi was spatially subdivided into ten submetros (refer to Fig. 1).

Kumasi had a network length of 1931.18 kilometres in 2011 comprising major and minor arterials, distributor or collector roads, and local roads (Metropolitan Roads Department, 2011). Out of this length, 136.4 kilometres $(7.1 \%)$ are the major arterials, which are the main roads leading into and out of the City including the Kumasi - Accra, Kumasi - Sunyani,
Kumasi-Mampong, Kumasi - Ahwia Nkwanta Bekwai and Kumasi - Bibiani roads. In addition, a further 110.39 kilometres $(5.7 \%)$ of the network constitutes the minor arterials, which are the roads connecting the local level roads to the major arterials such as Old Bekwai road, Asafo Roundabout - Zongo Police Station/ Roman Hill and Airport Roundabout - Manhyia roads. The district distributors/collectors are the roads next in the hierarchy and they link the minor arterials to the local roads; making up only 90.61 kilometres or $4.7 \%$ of all the City's roads. By far, the largest component of the network is made up of local roads; serving purely local traffic within the various residential areas and neighbourhoods. These roads constitute $1,593.78$ kilometres or $82.5 \%$ of the entire network and include all the unengineered roads serving various newly developing suburbs or neighbourhoods; including those on the periphery of the City.

The condition of the City's roads varies substantially; with $61.9 \%$ of the roads being in "Good" condition, 3.1\% in "Fair" condition, and $35.0 \%$ in "Poor" condition. This is an improvement on the 2007 estimates where $30 \%$ of the total urban road network was in "Good" condition, $15 \%$ in "Fair" condition, and $55 \%$ in "Poor" condition.

Five major arterial trunk roads and national highways converge in Kumasi with major transport terminals, which serve as interchange points for both passengers and cargo destined for different parts of the country (Adarkwa and Tamakloe, 2001). Adarkwa and Tamakloe (2001) further state that, Kumasi also performs several other functions of a national, regional and local nature, all of which generate their own traffic movements. According to a World Bank (2002) document entitled 'Cities on the Move', public transport serves very desperate markets. In many large cities, it serves the basic movement needs of those without private transport. In more congested cities, it may also aim to attract commuting trips of higher-income car owners or potential car owners. The problem is 


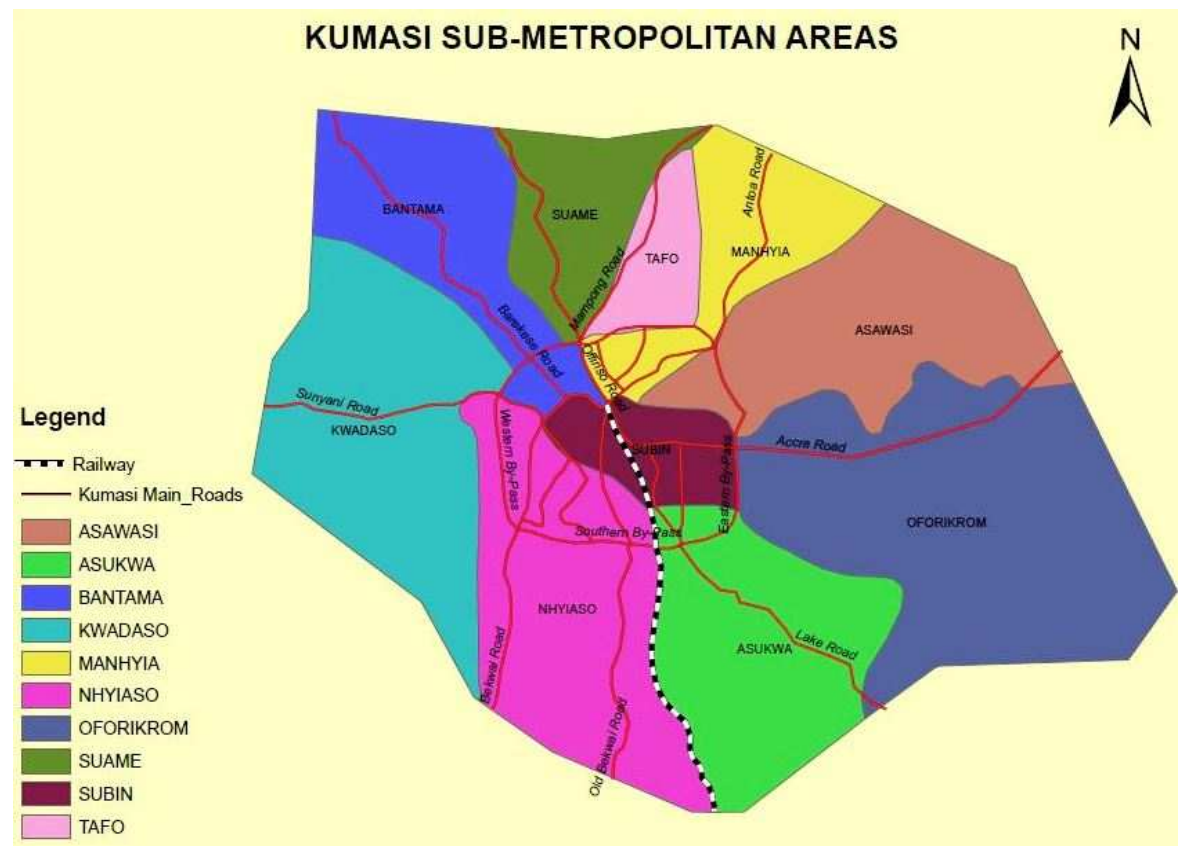

Fig. 1: Sub-Metros of the Kumasi Metropolitan Area

Source: Kumasi Metropolitan Assembly, 2013

that, the two markets are likely to require quite different price and quality combinations. For buses, this can be reconciled by the provision of higher-quality services (air-conditioned, seat only, and limited stops) on the same infrastructure (World Bank, 2002). The situation is however quite different in Kumasi where the services provided target the poor and those without cars or any other means of transport.

Public transport services in Kumasi, as is the case for the country as a whole, are provided predominantly by the private sector, which operates a mix of buses, minibuses and taxis. The overall quality of services of public transport is poor; most vehicles are old, and maintenance standards are extremely low. High vehicle maintenance costs arising partly from poor road conditions as well as the acute congestion on the urban roads limit the capacity of vehicle operators to invest in new vehicles. The increasing number of vehicles and their low ca- pacities result in long queues during the morning and evening rush hours. Poor quality of public transport characterised by inadequate vehicles, old vehicles, and low maintenance standards also make urban transport services poor. According to Abane (2010), the vehicles used for public transport services in Accra are characterised by $32.6 \%$ minibuses; $7 \%$ large buses and $39.2 \%$ shared taxis. In Kumasi, taxis, minibus, and buses constitute $43.9 \%, 31.7 \%$, and $14.0 \%$ respectively of the entire citywide vehicle fleet. Statistics from the Department of Urban Roads (2005) indicate that the average age of the vehicles within the industry is 18 years for Accra and 13 years for Kumasi, the two largest cities in Ghana. There are indications that the influx of more used vehicles into the Ghanaian market could compound the situation. 
STUDY APPROACH AND METHODOLOGY

The study was conducted in the 34 traffic zones of the Kumasi Metropolitan Area, delineated by the Department of Urban Roads in 1997. The delineation was done during a study of Land Use Forecast and Traffic Volume Growth Trends in Accra, Tema, Kumasi, Sekondi Takoradi and Tamale (refer to Fig. 2). The Department of Urban Roads undertook the delineation based on homogeneous social and economic characteristics such as income, housing quality, the general culture of the people, and the level of economic activities generated in the area.

The study focused on population, traffic patterns, and socio-economic characteristics within each of the traffic zones. The reason for the selection of these zones is that, they provide a better description of the urban travel characteristics within the metropolis. Data for this study were collected using questionnaires, observations and interviews, review of books, newspapers, journals and internet sources. Two main surveys were undertaken during the primary data collection. Example of data collected include income of commuters, fares paid, trip duration and employment status of commuters. The first survey spanned a period of three weeks while the second survey lasted for a period of one week. The second survey was to gather additional data as well as mop up all the gaps identified during the first survey. In all, 400 commuters were interviewed during the field surveys. The commuters, grouped into strata with definite characteristics such as income levels and trip making characteristics using the framework defined by Department of Urban Roads, were selected using the stratified sampling technique. The reason for the use of the stratified sampling method was to make sure that each stratum was represented in the final sample. This is very important for the

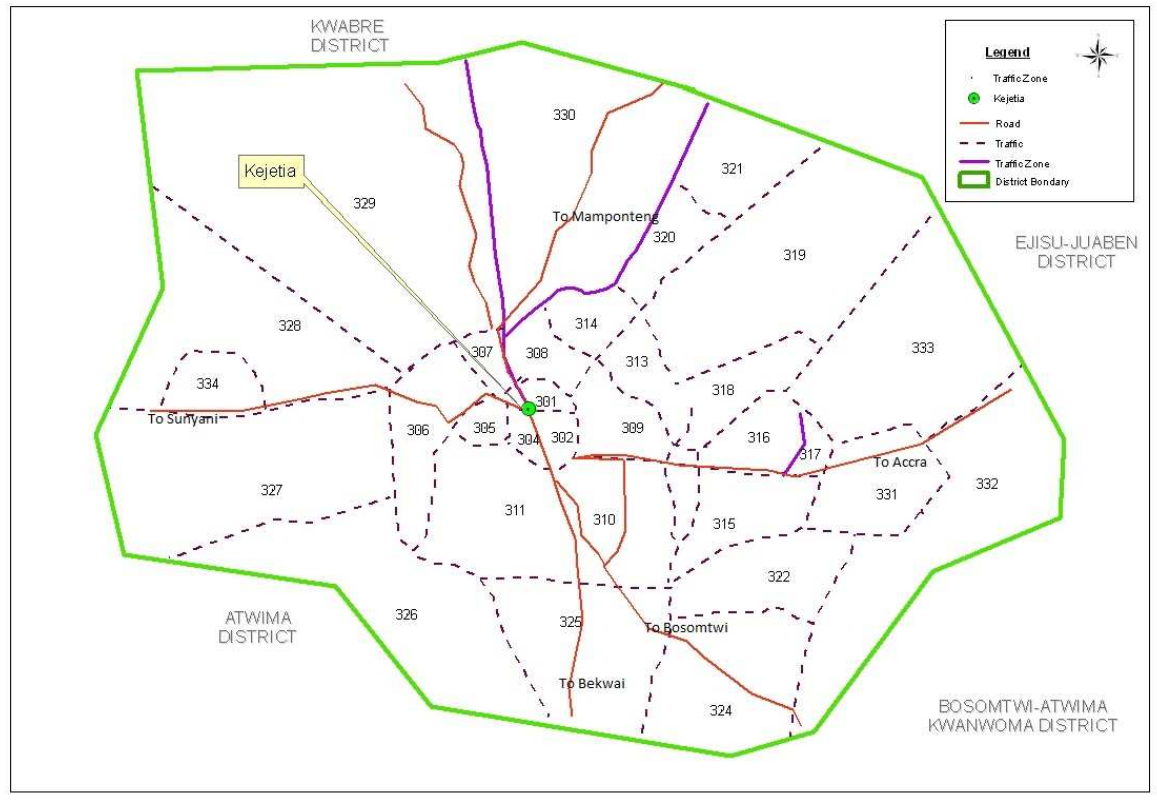

Fig. 2: Traffic Zones of the Kumasi Metropolitan Area Source: Department of Urban Roads, 1997 
study because it offered the researchers a more scientific basis for the data collection, which ultimately minimises errors and enhances generalisation of the findings. CHARACTERISTICS OF COMMUTERS
USING PUBLIC TRANSPORT SERVICES

Data from the field survey revealed that $54.3 \%$ of commuters were females while the remaining $45.7 \%$ were males. This shows a slight variation from the population structure of the entire Kumasi, which is $46.8 \%$ male and $53.2 \%$ female (Ghana Statistical Service, 2003). In spite of this, however, male commuters usually embark on about 5\% more trips than their female counterparts do (Okoko, 2004). This is because most of the trips are to places of work and men constitute the majority of the working population. According to Okoko (2004), it is generally believed that, households with higher educational level (secondary and tertiary) usually prefer using their own vehicles and, as such, do not patronise public transport services. It was however found in the study area that about $90 \%$ of the respondents have attained at least basic education, with about 59\% having completed either tertiary or secondary education. The implication of this for trip making is that, people with formal education are usually engaged in activities that may generate increased number of trips. On the average, the number of trips made by commuters on a typical weekday is estimated to be about one round trip between home and place of work. On a typical weekday, 1,451,424 commuter trips are made to work places while $1,125,135$ are made to social places. However, on a typical weekend, 1,383,916 commuter trips to social places such as the Kumasi Stadium are made while $1,260,151$ are made to work places. This is because most businesses within the metropolis fall under the informal sector where they operate during the weekends.

The time taken by commuters to make trips irrespective of the purpose in Kumasi ranges from 15 to about 80 minutes, along average route lengths of between $7.2 \mathrm{~km}$ to $14.5 \mathrm{~km}$. The mode used in undertaking the trips has an influence on the travel time along all the major arterials in the city. The trip duration for the various modes along the major arterials in the Metropolis is presented in Table 1. From the Table, it can be seen that, based on the vehicle mode, taxis, as expected, were the fastest; making a trip along the Lake Road in 18.10 minutes over a distance of 7.2 kilometres. This is because the number of stops made by taxis is usually fewer than the other modes due to the fewer commuters they carry and the ease of manoeuvrability. The minibuses come next with a travel time of 28.40 minutes while the Metro Transit buses make the trip in 30.65 minutes. The dominant mode for commuting in the city is taxi, which carries about $44 \%$ of respondents. The Minibuses and Metro Transit buses carried $32 \%$, and $14 \%$ of the respondents respectively. The estimated numbers of commuters carried by the various modes per day along the study routes are presented in Table 2 .

\section{FACTORS AFFECTING THE DEMAND FOR PUBLIC TRANSPORT SERVICE}

Just as the demand for other goods and services, the demand for public transport service is determined by several variables. Several studies have outlined variables such as vehicle kilometres operated (which can be used as a proxy for service level), income of passengers, trip duration, tariff levels, access to transport services, total population and employment status, which affect the demand for urban transport services. The level of influence of these variables on the quantity of public transport demanded depends on several socio-economic conditions. These variables are briefly discussed in the next section.

Vehicle Kilometres Operated (Service Level) According to Transport Research Laboratory (2004), a typical proxy for service level, in the sense of frequency, is vehicle-kilometres operated, although this may also change in response to network size and or period of day/week over which service is provided. The higher the vehicle kilometres operated, the greater the frequ- 
65 Poku-Boansi and Adarkwa

Table 1: Travel Time by Vehicle Modes per Trip along Major Arterials in Kumasi

\begin{tabular}{lcccc}
\hline Route name & $\begin{array}{c}\text { Route } \\
\text { length } \\
(\mathbf{k m})\end{array}$ & Taxi & Minibus & Metro Mass Transit \\
\hline Lake Road (Atonsu - Kejetia) & 7.2 & 18.1 & 28.4 & 30.65 \\
Accra Road (Ayigya - Kejetia) & 14.5 & 15.18 & 32.25 & 38.14 \\
Sunyani Road (Abuakwa - Kejetia) & 11.3 & 26.62 & 36.15 & 37.77 \\
Bekwai Road (Fankyenebra - Kejetia) & 11 & 18.18 & 26.71 & 35.67 \\
Mampong Road (Tafo - Kejetia) & 8 & 60.29 & 68.58 & 78.81 \\
\hline
\end{tabular}

Source: Field survey, 2008

Table 2: Commuter Trips per Vehicle Mode per Day in Kumasi

\begin{tabular}{lcccc}
\hline \multirow{2}{*}{ Route name } & \multicolumn{3}{c}{ Commuter-trips/Mode/Day } & Total \\
& Taxi & Minibus & Metro Mass Transit & \\
\hline Lake Road (Atonsu - Kejetia) & 245 & 980 & 2,740 & $\mathbf{3 , 9 6 5}$ \\
Accra Road (Ayigya - Kejetia) & 280 & 1,470 & 3,260 & $\mathbf{5 , 0 1 0}$ \\
Sunyani Road (Abuakwa - Kejetia) & 273 & 1,211 & 1,865 & $\mathbf{3 , 3 4 9}$ \\
Bekwai Road (Fankyenebra - Kejetia) & 280 & 644 & 1,845 & $\mathbf{2 , 7 6 9}$ \\
Mampong Road (Tafo - Kejetia) & 210 & 721 & 2,150 & $\mathbf{3 , 0 8 1}$ \\
Total & $\mathbf{1 , 2 8 8}$ & $\mathbf{5 , 0 2 6}$ & $\mathbf{1 1 , 8 6 0}$ & $\mathbf{1 8 1 7 4}$ \\
\hline
\end{tabular}

Source: Field survey, 2008

ency of vehicles used and the higher the demand for public transport services and vice versa. In Kumasi, vehicle kilometres operated is expected to increase when demand is high, especially in areas of the city with low vehicle population and ownership. The reverse is the same along rural roads where commuter trips are low.

Fares

The use of a public transport service normally requires the payment of fares. The fare level may be varied by time of day, day of week or even within a specific geographical zone, in order to influence patterns of demand and to maximize revenue of service providers. Transport services that charge higher fares usually record lower demand level. However, in Ghana, commuters' tend to have little say in the determination of fares. This is because commuters' concerns expressed in improved service level are not considered in the determination of fares. As such, higher fares charged do not necessarily reflect in lower demand. This is because commuters have limited options to choose from in relation to meeting their travel needs. 


\section{Income of Commuters}

The ability to pay for a journey affects the number of trips generated by a commuting household. Households with high income can afford to satisfy more of their travel demands than low-income households. In cities where population growth or change in population is minimal, traffic growth can come about in two ways: people making additional trips and people making longer journeys. In both situations, it is possible for trip production to increase with income, although the effect may not be very strong. According to Transport Research Laboratory (2004), the elasticity is in the range of 0.09 to 0.21 and in Ghana, income elasticity is estimated to be about 0.11 . It is therefore true that, increasing family income leads to greater trip production (Transport Research Laboratory, 2004). However, in Ghana, households with high income levels often use their private means of transport while medium to low income households often patronize public transport services. In a similar vein, high income households often embark on more trips than their counterparts in the medium and low income categories. It was found from the field survey that, high income households made about $35 \%$ more trips than those in the lower income category. In addition, about $88 \%$ of households using public transport services fell within the low and medium income category in Kumasi.

\section{Trip Duration}

This is the time a passenger takes to undertake a journey from an origin to a destination. It involves the time the passenger spends in walking to the nearest bus or vehicle stop, waiting for a vehicle, in-vehicle waiting time, journey time and walking time from the bus stop to final destination or home; where applicable. The time taken to undertake a trip affects the number of trips generated by a household member. Trips that take longer times are likely to be made rarely while those that can be made within a shorter period are likely to be made frequently. The situation in Kumasi was quite different, especially in relation to trips to work.
This is because most of the trips to workplaces are often seen as obligatory primarily on account of the fact that one can lose one's job because of absenteeism. Consequently, trip durations are made daily to work places by all income groups irrespective of their duration.

\section{Population}

This refers to the total number of people that are served by public transport services within a geographical area. The larger the population in an area, the higher the potential demand for public transport services while the reverse is also true. For example, from the field studies, passengers in traffic zones 16 (Ayigya), 33 (Kentinkrono, Nsene and Oduom) and 20 (Moshie Zongo and Sepe) (refer to Fig. 2) with high residential populations recorded the highest number of passenger trips of 98, 102 and 107 respectively.

\section{Employment Status of Commuters}

Most urban trips are generally to work places and as such, communities with larger numbers of people engaged in economic activities tend to demand higher public transport services; especially when private means of transport are limited. The higher demand for public transport services to work places is supported by the higher number of work related trips, which is about $52 \%$ of total number of trips recorded during the field studies.

\section{DEVELOPING THE DEMAND MODEL}

The rationale behind the demand model used in this study is generally found in economic theory; that is, ordinary demand function (Nicholson, 1995). The ordinary demand function, also known as the Marshallian demand, is based on maximising the consumer utility functions, which is subject to a budget constraint. In general terms, passengers choose among alternatives to maximize their utility; that is, to choose the package of trips, which they consider best among all the packages available to them, bearing in mind the various constraints which might be imposed on their choice. These constraints include the limited amount of both 
67

\section{Poku-Boansi and Adarkwa}

time and money available to the passengers and constraints imposed by the travel itself in relation to the travellers' choice of how much time to spend in travel. The Marshallian demand function as applied to this study can be stated as follows:

$X=d_{x}\left(P_{x}, P_{y}, I, s, t\right)$ (1), subject to

$\max U=u(X, s, \epsilon)$ (2), where

$X$ represents the quantity demanded, $d_{x}$ represents the quantity of good $x, P_{x}$ represents the price of $\operatorname{good} x, P_{y}$ is the vector of prices for other goods, $I$ is the available income, $s$ is a vector of socio-economic factors which translate into the measured attribute values of the transport services (i.e. cost, time, reliability, safety, and comfort), $\epsilon$ is a vector of stochastic disturbances, and $U$ is the utility of a trip maker.

Demand functions for commuter transport services are usually formed under the assumption of a utility maximising representative consumer, subject to his/her own budget constraint (Beko, 2003). Several studies such as the ones by Oum et al. (1992), and Oum and Watters (2000) have highlighted the fact that estimation for price elasticity of the demand for transport services shows elasticity that simultaneously includes income and substitution effects. For this study, however, the demand function reflects the behaviour of an individual whose preference dictates the particular functional form of the relationship. Many functions used in demand analysis are based on a linear or a log-linear relationship between the dependent and independent variables (Transport Research Laboratory, 2004). The linear model was deemed appropriate because, the phenomenon being studied is dynamic and on-going, and as such, can give a result, which is equally appropriate like the exponential and geometric models. For this study, the relationship between the independent variables as well as between the dependent and independent variables is linear as shown in the results of correlation analysis. Several variables are used as independent variables in estimating the demand model, including transport fares, trip duration, population within the traffic zones, household income, employment status of commuter, level of access to transport services, and the daily vehicle kilometres operated. Using these variables, the study sought to establish a demand model, which is linear in the form:

$$
\begin{aligned}
& D=a+b_{1} * T l+b_{2} * T D+b_{3} * P+b_{4} * I n c+b_{5} \\
& * \text { empst }+b_{6} * A S+b_{7} * V K O+\varepsilon \ldots \ldots \ldots . .(3) \\
& \text { Where } D=\text { Demand; } \\
& \text { A }=\text { Constant } \\
& B_{1}-b_{7}=\text { Beta coefficients; } \\
& \mathrm{Tl}=\text { Fares; } \\
& \text { TD }=\text { Trip duration } \\
& P \quad=\text { Population; } \\
& \text { Inc }=\text { Income of households; } \\
& \text { empst = Employment status; } \\
& \text { AS = Access to transport } \\
& \text { services; } \\
& \mathrm{VKO}=\text { Vehicle kilometers oper } \\
& \text { ated; and } \\
& \varepsilon=\text { Error term }
\end{aligned}
$$

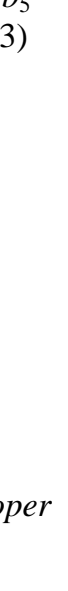

The error term, which is also the disturbance term used in the equation is assumed or equated to zero. The reason is that one assumption of the linear regression model is that, the error term has $50 \%$ chance of being positive and $50 \%$ chance of being negative. This therefore explains the reason why the error term is predicted to be zero (Field, 2005).

The stepwise multiple regression model was used in estimating the ordinal least square (OLS) regression in stages. The method, according to Garson (2006), includes in the equation, the independent variables that best correlate with the dependent variable. In the subsequent stages of building the model, Garson (2006) argues that the remaining independent variable with the highest partial correlation with the dependent variable is entered, controlling the first. The process is repeated at each stage partially for previously entered independent variables until the addition of a remaining 
Determinants of public transport services in Kumasi... 6

independent variable does not increase the coefficient of multiple regressions $\left(R^{2}\right)$ by a significant amount. The t-test statistic was also used to assess the significance of the individual beta coefficients in the model. A common rule of thumb, according to Field (2005), is to drop from the equation all variables not significant at 0.05 levels or better. Like all significance tests, the t-test assumes randomly sampled and distributed data.

For this study, the two-tailed t-test was used because, the model seeks to establish relationships without any specific direction and also aims at establishing if there is any difference or change between the variables used in estimating the models. In other words, two plausible outcomes are expected from the statistical testing. The criterion for selecting or dropping an independent variable from the final demand model was based on their significance probability and correlation coefficients. Independent variables with significance probability of less than or equal to 0.05 were entered while those with significance probability greater than or equal to 0.10 were dropped. This is because variables with significance probability of greater than or equal to 0.10 do not contribute significantly to the overall variability in the demand model. This was done in spite of the fact that some of them had high correlation coefficients. Table 3 presents the results of the correlation analysis between the defined variables. From the Table, it can be seen that the correlation between demand for public transport and transport fares was significant but an inverse one.

This means that, there is a strong tendency for transport fare increases and demand to move together in a linear manner but with a negative slope. In other words, increases in transport fares serve as a disincentive in patronising public transport services in the study area. This confirms the estimated elasticity of the demand value of 0.11 for public transport services by Poku-Boansi (2008). According to Frank and Bernanke (2003), it is the ratio of the propor-

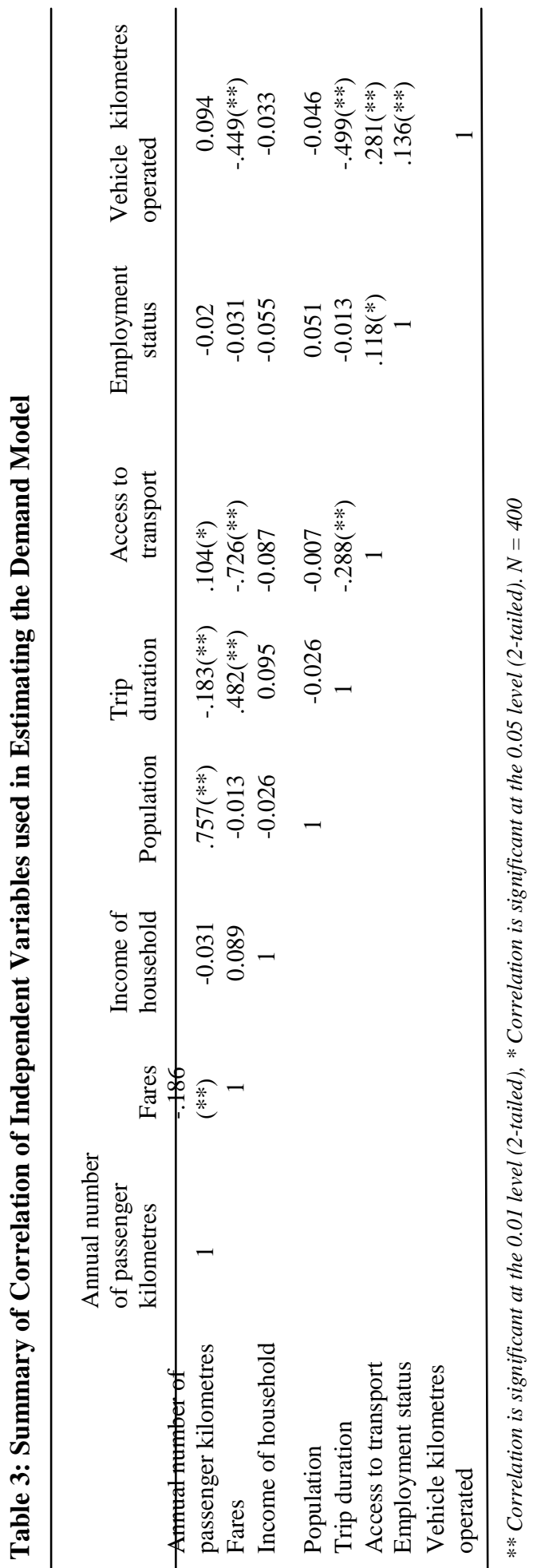

Journal of Science and Technology @ C KNUST December 2013 
tional change in patronage to the proportional change in fares. It has a negative value when, as is usually the case, fares and patronage are inversely related: an increase in fares leads to a decrease in patronage. Elasticity of demand is the percentage change in the number of trips that will occur in response to a one percent change in any one of the 'prices' of travel. In transport terms, elasticity is not simply the ratio by which travel frequency rate shrinks in response to a one-time increase in fares or travel time, but rather, the instantaneous rate of change along the demand curve. In a similar vein, trip duration is likely to move in a linear like fashion with a negative slope. These relationships were generally expected since they portray the situation within the urban transport service industry. The relationship between demand and population is a very strong one with a correlation coefficient of 0.757 . This means that, an increase in population will have a tendency to move in a linear direction with the demand for public transport services in $\mathrm{Ku}$ masi.

\section{The Demand Function}

The results from the correlation analysis between annual number of passenger kilometres and vehicle kilometres operated, access to transport and household income revealed correlation coefficients of $0.260,0.744$, and 0.839 respectively. From these figures, it can be concluded that, household income, access to transport and vehicle kilometres operated were not significant in the overall model since their significance probabilities are higher than the criterion value of 0.05 needed to be included in the model; implying that, they are not robust enough to allow for their inclusion in the model. In one out of five cases, they could result in an error. In a similar vein, four variables were selected as being the key independent variables contributing to the demand model. These independent variables are fares, population level, trip duration, and employment status. Based on the earlier criterion, these independent variables were selected because of their significance probability.
From the regression output, it was realized that, the significance probability for population, fares, trip duration and employment status were $0.000,0.000,0.004$, and 0.044 respectively, which were all less than the 0.05 needed for inclusion in the final model. From the regression output, it was realized that, population was the main independent variable contributing about $66.4 \%$ to the entire coefficient of multiple determination $\left(R^{2}\right)$ of the model; implying that, $66.4 \%$ of the variations in transport demand can be explained by variations in population of the traffic zones. The next variable to be picked by the model was trip duration, which contributes $10.1 \%$ to the model. Fares contribute $9.4 \%$ to the model while employment status contributes $1 \%$ to the model. In a sense, the contribution of fares to the variation in the dependent variable would seem to indicate that, users of public transport services in Kumasi are somehow captive to these services to the extent that increases in fares do not appear to affect patronage levels.

Table 4 is the summary of the multiple stepwise regression analysis for the demand model. It can be seen from the table that, the regression coefficient of the model is 0.932, implying a reasonably strong linear relationship between annual number of passenger kilometres as a dependent variable and population, fares, trip duration and employment status as independent variables. The $\mathrm{R}^{2}$ of the model is 0.869 while the adjusted $\mathrm{R}^{2}$ is 0.864 . This means that about $87 \%$ of the variability in demand can be explained by variations in the independent variables. The F value of the model, which is used to test the significance of correlation coefficient $(\mathrm{r}), \mathrm{R}^{2}$, and the regression model as a whole is 153.29 and it is significant at less than 0.001. Thus, there is a significant linear relationship between the dependent variable and the independent variables in the model; particularly population. As population of the traffic zones increases, this tends to impact travel needs and requirements directly.

From the forgoing discussions, the final output 
Determinants of public transport services in Kumasi... 70

Table 4: Summary of Model Parameters and their Attributes for Demand for Public Transport Services

\begin{tabular}{lccc}
\hline Independent variables & $\begin{array}{c}\text { Unstandardized } \\
\text { Coefficients }\end{array}$ & $\begin{array}{c}\text { Standardized } \\
\text { Coefficients }\end{array}$ & t values \\
\hline Constant & 163093244.02 & & $3.528^{* *}$ \\
Population & 4302755.55 & .756 & $24.191^{* *}$ \\
Fares & -72226.23 & -.130 & $-3.646^{* * *}$ \\
Trip Duration per Kilometre & -5850058.76 & -.102 & $-2.858^{* * *}$ \\
Employment Status & -77682443.96 & -.063 & $-2.022^{* *}$ \\
Observations & 400 & & \\
$R$ & 0.932 & & \\
$R^{2}$ & 0.869 & & \\
Adjusted $R^{2}$ & 0.864 & & \\
$F$ & 153.29 & & \\
\hline
\end{tabular}

Note: $.01<p<.05^{* *} p<.01 ; * *:$ very significant; $R^{2}$ : Coefficient of determination; $R$ : regression coefficient (estimate of the change in the dependent variable that can be attributed to a change of one unit in the independent variable).

for the demand model obtained from the multiple stepwise regression analysis using the standardized regression coefficient is given as:

$D=0.756 \times P o p-0.130 \times T l-0.102 \times T D-$

$0.063 \times(1+\log ($ empst $))$

$\begin{aligned} \text { Where D } & =\text { Demand } ; \\ \text { Pop } & =\text { Population; } \\ T l & =\text { Fares; } \\ T D & =\text { Trip duration; and } \\ \text { empst } & =\text { Employment status; }\end{aligned}$

A positive and significant coefficient of 0.756 as shown in Table 4 demonstrates the importance of population on the demand for urban transport services in the Kumasi Metropolis. This implies that high population is more likely to have a greater tendency towards increased demand for urban transport services as people will use the service. This finding is consistent with those established by the Transport Research Laboratory (2004). A further look at Table 4 reveals that fares charged, trip duration and the employment status of respondents have a negative and highly significant impact on the demand for public transport services in the city of Kumasi. These results point out the importance of improved service level and the financial resources availability to urban commuters in their demand for public transport services. These findings appear to support those established by Carruthers et al. (2005) in their work on affordability of public transport in developing countries.

The model derived from the regression analysis is aimed at estimating demand for urban public transport services in Kumasi. From the equation, it can be seen that, population, fares, trip duration and employment status influence the demand for public transport services. The implication of these findings from the demand analysis in the public transport service policy formulation cannot be underestimated. For example, the role of tariff levels in the demand for urban transport services in Kumasi calls for the involvement of stakeholders seeking passenger wellbeing in the pricing of urban transport ser- 
71

vices. This is because, the involvement of all stakeholders in the pricing of urban transport services is one of the approaches that can be adopted to ensure sanity and fairness in the pricing of the service as well as remove doubts in the minds of the commuters. It is worth noting that, the fairness of the price incidence; that is, the amount paid and who is paying what, as well as the levels of the price, has a major influence on its acceptability. Consequently, computing transport cost using the appropriate pricing model based on fair and efficient pricing (Viegas and Macario, 2003) is also one of the aspects to consider as of utmost importance and must be participatory.

Another policy worth pursuing is the use of large capacity buses to meet the demand of the large population in Kumasi. This should be done by providing them with exclusive lanes to help reduce travel time to make them the preferred option of commuters. This use of large capacity buses is because population serves as the single largest determinant of demand for urban transport services in Kumasi. In view of this, it is important to encourage the use of large but new vehicles in the operation of public transport services since it could help in reducing the cost of providing the services. This is because the unit price of vehicle operating inputs has direct impact on vehicle operating cost. In addition, the use of large capacity buses is gradually gaining grounds within the interurban transport service industry and there is a possibility that the same can be done within the intra-urban transport service industry, given the increasing population and demand for transport services in urban centres.

\section{CONCLUSION}

Public transport services serve most people in the urban areas; especially, the low and middleincome earners who see this form of transport as the most affordable means of commuting. The study reports on the factors that influence the demand for public transport services in the Kumasi Metropolis. These factors include population, fares charged, trip duration and employment status of commuters.

\section{REFERENCES}

Abane, M. A (2010). Travel Behaviour in Ghana: Empirical Observations from Four Metropolitan Areas. Journal of Transport Geography. 189 - 376.

Adarkwa, K. K., and E. K. A Tamakloe (2001). Urban Transport Problems and Policy Reforms in Kumasi. In Adarkwa, K. K and J, Post (Eds); The Fate of the Tree: Planning and Managing the Development of Kumasi, Ghana, Accra: Woeli Publishing Services.

Beko, Jani (2003). Demand Functions for Services of Public Railway Passenger Transportation: An Empirical Analysis for Slovenia. Managing Global Transitions 1 (2): 135 152.

Carruthers, R., M. Dick, and A. Suarkar (2005). Affordability of Public Transport in Developing Countries. Transport Paper No. 3. Transport Sector Board. The World Bank Group. Washington, D. C.

Department of Urban Roads (2005). Bus Rapid Transit Options Identification and Prefeasibility Study. Accra, Government of Ghana, Ministry of Transportation. (Draft Final Report).

Department of Urban Roads (1997). Land Use Forecast and Traffic Volume Growth Trends in Accra, Tema, Kumasi, Sekondi - Takoradi and Tamale. Accra, Government of Ghana/ Ministry of Roads and Highways.

Field, A (2005). Discovering Statistics Using SPSS. London. Sage Publications Limited. Second Edition.

Frank, Robert and Ben Bernanke (2003). Principles of Economics. New York, McGrawHill Irwin.

Garson, D. (2006). Multiple Regression. Re- 
trieved from: http://www2.chass.ncsu.edu/ garson/pa765/regress.htm, on December 6, 2006.

Ghana Statistical Service (2003): Ghana Demographic and Health Survey. Accra.

Kumasi Metropolitan Assembly (2013). Development Plan Kumasi Metropolitan Area. Kumasi: Kumasi Metropolitan Assembly.

Kwakye, E. A, J. Turner and M. Grieco (1994). A Tale of Two Cultures: Ethnicity and Cycling Behaviour in Urban Ghana. Record 1441. Washington D.C: Transportation Research Board.

Lee, S, H. Y Lee and H. J. Park (1974). Estimating Price and Service Elasticity of Urban Transportation Demand with Stated Preference Techniques: Case of Korea. Transportation Research Record. National Research Council, Washington DC. ISSN 0361-1981.

Mbara, T. C. (2006). Coping with Demand for Urban Passenger Transport in Zimbabwe: Challenges and Options. Paper presented to the 25th Annual Southern African Transport Conference, South Africa, 10 - 13 July.

Metropolitan Roads Department (2011). Urban Roads Length, Surface Type, and Condition. Kumasi, Ghana.

Nicholson, W. (1995). Microeconomic Theory: Basic Principles and Extensions. Philadelphia: The Dryden Press.

Okoko, E. E (2004). Modelling Car Ownership in a Developing Country: Empirical Data from Akure, Nigeria. Indian Highways, 57 67.

Okoko, E. E. (1998). The Demand for Paratransit Transport Services in Nigerian Towns: -
The Case of Motorcycle Transport. Journal of Transport Studies. 2: 4-14

Oum, T. H., and W. G. Watters (2000). Transport Demand Elasticities. In Handbook of Transport Modelling (Ed). D. A. Hensher and K. J. Button. Amsterdam: Pergamon.

Oum, T. H., W. G. Watters, and J. S. Yong (1992). Concepts of Price Elastic Elasticities of Transport Demand and Recent Empirical Estimates: An Interpretative Survey. Journal of Transport Economics and Policy. 26: 139. 54.

Poku-Boansi, M (2008). Determinants of Urban Transport Services Pricing in Ghana: A Case Study of the Kumasi Metropolitan Area. PhD Thesis submitted to the Board of Postgraduate Studies, Kwame Nkrumah University of Science and Technology, KNUST, Kumasi Ghana.

Transport Research Laboratory (2004). The Demand for Public Transport: A Practical Guide. TRL Report, Number 593. Crowthorne, UK.

UN-HABITAT (2008). The State of African Cities 2008: A Framework for Addressing Urban Challenges in Africa. Nairobi, Kenya.

Viegas, J. M and R. Macario (2003). Acceptability of Price Changes in Urban Mobility'. In Schade, J and B. Schlag (eds) Acceptability of Transport Pricing Strategies. Oxford, Elsevier.

World Bank (2002). Cities on the Move. A World Bank Urban Transport Strategy Review. Washington, D.C., The World Bank.

World Bank (2004). Urban Transport Overview. Washington D.C., The World Bank. 